\title{
Task Based Risk Assessment For Human Factors Impact On Aviation Maintenance Deviations: A case study on three specific tasks and their operational implications
}

\author{
Stephen Caffrey \\ Technological University Dublin, D14125618@mutudublin.ie \\ Laís Veloso Lara \\ Technological University Dublin, d18124096@mydit.ie \\ Christopher Murtagh \\ Technological University Dublin, d18124998@mydit.ie
}

See next page for additional authors

Follow this and additional works at: https://arrow.tudublin.ie/schfsehcon

Part of the Aviation Safety and Security Commons

\footnotetext{
Recommended Citation

Caffrey, S., Lara, L.V. \& Murtagh, C. (2019). Task Based Risk Assessment For Human Factors Impact On Aviation Maintenance Deviations: A case study on three specific tasks and their operational implications. Proceedings of the 29th European Safety and Reliability Conference (ESREL), Leibniz Universität Hannover, Germany. doi:10.3850/978-981-11-2724-3_1122-cd
}

This Conference Paper is brought to you for free and open access by the School of Food Science and Environmental Health at ARROW@TU Dublin. It has been accepted for inclusion in Conference papers by an authorized administrator of ARROW@TU Dublin. For more information, please contact arrow.admin@tudublin.ie, aisling.coyne@tudublin.ie,gerard.connolly@tudublin.ie.

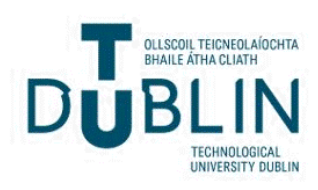


Authors

Stephen Caffrey, Laís Veloso Lara, Christopher Murtagh, Maria Chiara Leva, and Victor Hrymak

This conference paper is available at ARROW@TU Dublin: https://arrow.tudublin.ie/schfsehcon/29 


\title{
Task based risk assessment for human factors impact on aviation maintenance deviations: a case study on three specific tasks and their operational implications
}

\author{
Stephen Caffrey \\ Technological University Dublin, Ireland. E-mail: d14125618@mydit.ie \\ Laís Veloso Lara \\ Technological University Dublin, Ireland E-mail:d18124096@mydit.ie \\ Christopher Murtagh \\ Technological University Dublin, Ireland.E-mail:d18124998@mydit.ie \\ Maria Chiara Leva \\ Technological University Dublin, Ireland. E-mail: Chiara.leva@dit.ie \\ Victor Hrymak \\ Technological University Dublin, Ireland.E-mail:victor.hrymak@dit.ie
}

This paper investigates human performance on a set of selected tasks in an aviation maintenance organisation, where a significant prevalence of unsafe acts and conditions were observed. The methodology began with visual inspections of the work environment. Semi structured interviews were then undertaken to gain an insight into the job demands and critical issues reported by front line operators. Three representative critical tasks were then selected for a detailed task analysis. This fed into a task based risk assessment that mapped out safety critical deviations together with timelines for nominal and deviation paths. The likelihood and severity of potential outcomes were estimated in terms of loss of productivity. Task performance was assessed in terms of the likelihood of failure and compared with a monetised risk exposure for both nominal paths and when short cuts and deviations occurred.

Keywords: Human Factors, Aviation Maintenance, Task Analysis.

\section{Introduction}

Aviation maintenance is a highly regulated industry which operates to the highest internationally recognised safety standards. However, significant accidents are still occurring and human factors play a significant role in many of them. (Boeing 2003, and Hawkins 1993).

Aviation maintenance is intrinsically very vulnerable to human errors as recognised by the U.S. National Transportation Safety Board, 1979. However, explicit and systematic consideration for human factors in this domain only started to take place around 1990 (Mellema, 2018).

Human error can be defined as the failure to complete a specific task that could result in scheduled operations interruption or damage to property and equipment (Reason, 1990). In aviation maintenance, examples of human error include the installation of wrong or loose parts, access panels not secured, and ground lock pins not removed from landing gear before leaving the hangar (Latorella and Prabhu, 2000).

Graber and Marx (1993) outlined 122 maintenance errors that took place over a 2 years period. The underlying issues included; omission (56\%); installation issues $(30 \%)$ wrong parts $(8 \%)$, and other $(6 \%)$. These results endorse the relevance of humans during aviation maintenance (Dhillon and Liu, 2007).

A "Dirty Dozen" human factors are recognised to be the main causal agents of accidents in the aviation industry which are here summarised as; a lack of communication, knowledge, teamwork or assertiveness, distractions, fatigue, pressure, lack of awareness, stress, and complacency (Mellema, 2018 and Dupont, 1997).

\subsection{Background to the study}

This paper presents an investigation into the operational implications of deviations in human performance. It used a set of selected tasks, where repeated deviations were detected in a

Proceedings of the 29th European Safety and Reliability Conference.

Edited by Michael Beer and Enrico Zio

Copyright (c) 2019 European Safety and Reliability Association.

Published by Research Publishing, Singapore.

ISBN: 978-981-11-2724-3; doi:10.3850/978-981-11-2724-3_1122-cd 
particular maintenance organisation. As the study developed, a cost benefit analysis was introduced in order to quantify costs associated with historical accidents and resulting monetised risk exposures that organisations encounter when deviations and procedural short cuts occur. This approach was influenced by Virovac, Domitrovic and Bazijanac (2017). These authors also investigated the prevalence of human error in an aviation maintenance organisation, fully compliant with European Aviation Safety Agency (EASA) and ICAO Human Factor Guidelines for Aircraft Maintenance Manual (Doc 9859-AN/474).

The participating organisation in this study, was interested in how unsafe acts and shortcuts could create a false sense of added value. This value was thought to have originated from the highly competitive nature of the business which demands constant high levels of productivity and performance including short turnaround times for all maintenance interventions.

A further question was how a human factors based approach could highlight any hidden costs and monetised exposure connected with the observed procedural short cuts and deviations. It was then possible to design a proactive safety program, aimed at increasing both productivity and safety for maintenance operations.

\subsection{Current data on accident and incident performance in the company}

The organisation has a recent history. Operations started in 2009 and the focus on accident reporting was not fully developed till late 2013. Therefore it was assumed that accident records up to 2013 underestimates the safety reality of the production floor. The overall reporting culture in the organisation is still an underlying problem. The following table represents the number of lost time accidents per year with the number of aircraft which passed through the hangar from 2009 to 2018.

Table 1: Representation of the number of lost time accidents per year and the number of aircraft through the hangars.

\begin{tabular}{cccc}
\hline Year & $\begin{array}{c}\text { No. of } \\
\text { accidents }\end{array}$ & $\begin{array}{c}\text { No. of lost } \\
\text { time accidents }\end{array}$ & No. of aircraft \\
\hline 2009 & 1 & No data & No data \\
\hline 2010 & 4 & No data & No data \\
\hline 2011 & 8 & No data & No data \\
\hline 2012 & 24 & No data & 51
\end{tabular}

\begin{tabular}{cccc}
\hline Year & $\begin{array}{c}\text { No. of } \\
\text { accidents }\end{array}$ & $\begin{array}{c}\text { No. of lost } \\
\text { time accidents }\end{array}$ & No. of aircraft \\
\hline 2013 & 17 & No data & 59 \\
\hline 2014 & 29 & No data & 61 \\
\hline 2015 & 36 & No data & 47 \\
\hline 2016 & 38 & 11 & 51 \\
\hline 2017 & 42 & 16 & 72 \\
\hline 2018 & 69 & 29 & 50 \\
\hline
\end{tabular}

Table 1, demonstrates a steady increase in accidents, but under-reporting must also be borne in mind. As a result of an internal safety awareness programme in late 2017 the most reliable data is from 2018. In 2018 there was a total of 29 accidents where the injured party was unfit to work for periods ranging from 1 to 55 days. As section 5 in this paper will show, the financial implication of these days lost underlines the result that "accidents cost money".

\section{Methodology}

Figure 1 details the step by step methodological approach applied in this study. Data generation began with visual inspections of the work environment to observe safety related conditions and behaviours. A total of 77 such inspection were conducted. This was followed by $20 \mathrm{semi}$ structured interviews that were undertaken to gain an insight into the job demands and critical issues reported by front line operators. Three representative critical tasks were then selected. This allowed for detailed task analysis which was then fed into a task based risk assessment to map out safety critical deviations together with timelines for the nominal and deviation paths.

Following this step, the likelihood of deviations were estimated along with the severity of potential outcomes in terms of loss of productivity (based on past-recorded incidents). Finally, task performance was fiscally assessed by; comparing monetised risk exposures for nominal paths and alterative task flows incurred when short cuts and deviations were present. 


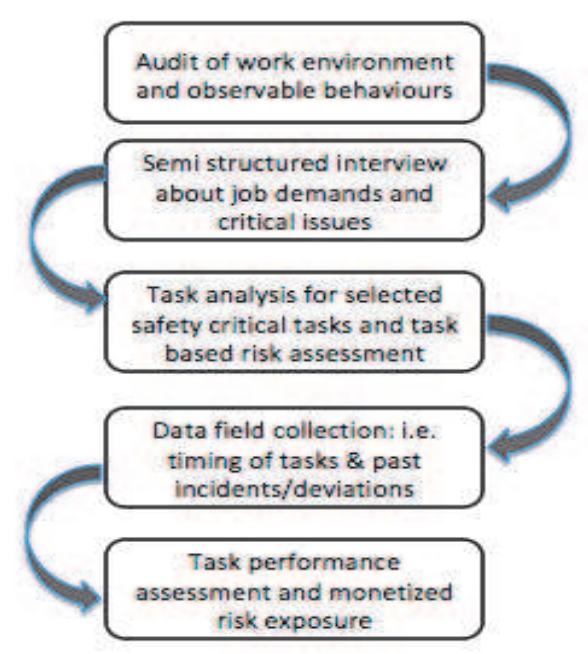

Fig. 1. Methodological approach

\subsection{Audit of work environment and visual inspection step}

The audit included visual inspection and the collection of relevant documentation. Visual inspection is defined as a traditional manual activity that involves careful and critical assessment of an object or area with reference to a predefined standard (Drury and Watson, 2002). Drury's two stage model of inspection performance is the most revered and commonly cited within the domain of Visual Inspection. The model is encompassed by a 'Search' and 'Decide' methodology. The 'Search' aspect of the model contains the investigation of an item or area against a pre-conceived set of standards. Whilst, 'decide' encompasses whether or not the fault exceeds or falls short of said standards.

This study also developed checklists to benchmark the levels of safety compliance. Inspections were conducted within pre-defined zones, which related to areas of high incident rates gathered from the analysis of historical accident reports available (see Table 2).

Table 2: Working Zones inspected

\begin{tabular}{cc}
\hline Zone & Position on aircraft \\
\hline 1 & Left wing above \\
2 & Left wing below \\
3 & Right wing above \\
4 & Right wing below \\
5 & Left engine \\
6 & Right engine \\
\hline
\end{tabular}

\begin{tabular}{cc}
\hline 7 & Left landing gear \\
8 & Right landing gear \\
\hline
\end{tabular}

\subsubsection{Audit and Inspection results}

There were a total of 77 inspections conducted in all zones. These inspections revealed an overall mean level of non-compliance with required procedures of circa $19 \%$. The worst visual inspection result recorded circa $49 \%$ noncompliance.

Examples of non compliance included poor housekeeping standards $(\mathrm{PH})$, not wearing personal protection equipment (PPE) the presence of slip, trip and fall hazards (STF) and chemical safety issues. Overall levels of non compliance are presented in Figure 2.

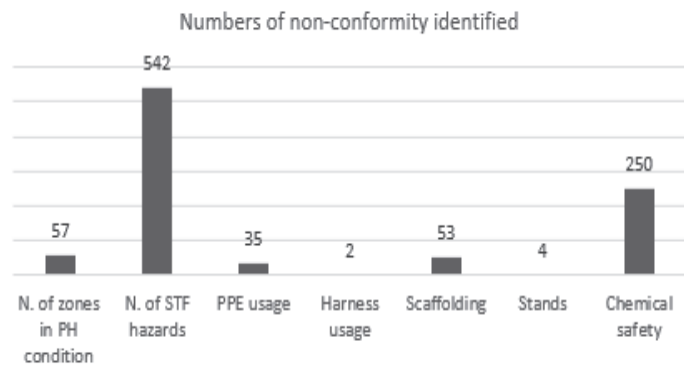

Figure 2 - Number of non-conformity identified during the audits versus items.

Poor standards of housekeeping were not only connected to a higher level of safety hazards. They also potentially related to productivity loss. For example tools not being in their designated place meant that operators had to search for the appropriate equipment, which in some cases was not available within the time window allocated to perform the activity. Housekeeping was measured in terms of high, moderate and low level of compliance. Figure 2 also demonstrates that poor housekeeping issues were identified as the most prevalent safety related issue and observed in circa $74 \%$ of all visual inspections completed. Examples of poor housekeeping also included tools, rags, liquid spills, electrical cables, and air hoses left scattered around the workplace, These were classified as slip, trip and fall hazards.

The data obtained presented a number of issues with regards to Personal Protective Equipment 
(PPE). High levels of non-compliance were observed among operators in the landing gear zone (Table 2). Of the 18 inspections conducted on the landing gear area, there were 4 instances of operators not wearing any eye protection while completing work on the landing gear. This allowed potential eye splashes from "Skydrol", a hazardous hydraulic fluid which is able to cause severe eye or skin irritation requiring medical attention.

During the semi-structured interviews, a member of staff reported: "if you get Skydrol in the eye, it feels like you have been hit on the head with a bat". Accidents involving Skydrol therefore led to operational issues connected to delays, work interruptions and poor hand over as well as quality issues in production.

\subsection{Interview step}

Rubin and Rubin (2005) contend that semi structured interviews create a flexible way in which to structure an interview. Furthermore, this mode of interview allows the interviewer to probe and expand on areas but extract a greater understanding and more detailed responses.

Hence semi structured interviews were employed to gain, a greater understanding of the domain and the human factors relating to the specific tasks. They were also used to probe possible shortcuts and deviations from required procedures.

Interviews were conducted with 20 maintenance engineers with varying levels of experience and approvals. Interviewees were selected on the basis of assuring a representative sample and also took into account previous accident reports and regulatory inspections results.

\subsubsection{Interview results}

The interview data presented an underlying feeling of 'pressure' amongst the operators, to complete required works within a set period of time, which is set by the sales team as part of the work scope and contractual agreement with the aircraft owner.

The interview data also raised about the standards of housekeeping and their association with possible accidents. Furthermore, it was noted by one interviewee that the housekeeping standards had been underlined as an issue by a regulatory body during a routine audit.

\subsection{The Task analysis step}

Task analysis consists of investigating the interaction between human capabilities and a system in order to reach a goal. It can increase productivity, identify human error and hazards as well as collect inputs for human reliability assessment (Kirwan and Ainsworth, 1992). In this study task analysis was used to build a detailed picture of three pre-selected maintenance tasks before analysing them from a human performance perspective.

Procedural tasks descriptions were derived from standard operating procedure manuals and applicable aviation authority requirements. Flowcharts were then used to illustrate the sequence of mapped steps. Potential deviations associated with each process step were identified and actual shortcuts and deviations were observed during the conduct of the three selected task. In addition each task was timed in order to determine the ideal duration of the process. The timing was performed for the nominal flow (task with no deviation) and for the possible deviation paths considered too (the execution of the each task with deviations). Timings were gathered during five repetitions of each task and path.

\subsubsection{Time task based}

By timing the process on five occasions it was possible to identify the mean duration of each nominal task and of each different deviation path taken. The time taken for recovery and corrective actions implemented was also obtained.

\subsubsection{Removal of the fuel filter}

During his interview, the supervisor of this task reported not closing a particular valve as the most significant deviation. This could potentially result in eye injuries from a splashes of jet fuel. If this occurs, circa one day would be lost from; treating the injury, finding replacement staff and delays in finishing the task.

This hazard can be prevented by wearing eye protection but the non use of PPE was observed in circa $60 \%$ of the time. The mean time to 
correct this deviation by going to fetch and wear the PPE was 3 minutes and 40 seconds.

Table 3. Timing of the removal of the engine filter

\begin{tabular}{ccc}
\hline Task & Aircraft type & Task time \\
\hline A320 & $0: 30: 11$ \\
Removal of & A319 & $0: 28: 52$ \\
engine filter & Boeing 737-300 & $0: 31: 17$ \\
& A320 & $0: 29: 03$ \\
& A320 & $0: 36: 08$ \\
\hline \multirow{3}{*}{ Average task duration } & $0: 31: 06$ \\
\hline
\end{tabular}

\subsubsection{Removal of the electric pump}

According to procedures the hydraulic line must be shut off meaning there is no pressurized fluid in the line. However residual skydrol can still exist in the general working area. The deviations observed in this task were; not using PPE during the easing of tightened nuts and bolts. As reported during interviews seized nuts can occur due to inadequate lubrication, corrosion or damage.

Table 4. Timing of the removal of the electric pump

\begin{tabular}{ccc}
\hline Task & Aircraft type & $\begin{array}{c}\text { Task } \\
\text { time }\end{array}$ \\
\hline $\begin{array}{c}\text { Removal of electric } \\
\text { pump on landing } \\
\text { gear }\end{array}$ & A320 & $2: 51: 05$ \\
& A319 & $2: 46: 18$ \\
& A320 & $2: 13: 49$ \\
& A320 & $2: 49: 58$ \\
& Average task duration & $2: 02: 14$ \\
\hline
\end{tabular}

\subsubsection{Removal of fuel tank panel}

Seized nuts and not wearing PPE were also observed in this task. In this case, three different pieces of equipment may be necessary to remove nuts and bolts dependent on how easy they are to remove.

Table 5. Timing Removal of fuel tank panel

\begin{tabular}{ccc}
\hline Task & Aircraft type & Task time \\
\hline $\begin{array}{c}\text { Removal of fuel } \\
\text { tank panel on the } \\
\text { wing }\end{array}$ & A320 & 0:24:45 \\
& A319 & $1: 21: 14$ \\
& Boeing 737-300 & $0: 16: 42$ \\
\hline
\end{tabular}

\begin{tabular}{cc} 
A320 & $1: 06: 13$ \\
A320 & $2: 39: 34$ \\
\hline Average task duration & $1: 09: 42$ \\
\hline
\end{tabular}

\section{Task based risk assessment}

\subsection{Removal of an electric pump}

The electric pump itself is located in the wheel well of the landing gear. In completing this task there is again a possibility of coming in contact with hydraulic fluid (Skydrol). Therefore, prior to any works a depressurisation of the hydraulic system closely followed by the draining of all fluid in the line into the appropriate chemical resistant container is required. The main hazard during this task is eye contact with hydraulic fluid in the line (Skydrol). In 2018 there was eight such accidents. Overall this task is not carried out frequently but is considered high risk due to high volumes of hydraulic fluid present.

\subsection{Removal of the fuel filter element}

The removal of the fuel filter element presents different hazards. The removal of the filter itself is a fairly straightforward task, but this can lead to issues of complacency. The task itself should only take about $15 \mathrm{mins}$ to complete without any deviations. However a direct result of this simplicity staff tended not to wear bump caps. The engine cowling in the vicinity has sharp edges, which have proven to cause lacerations to the head over the years. Although not evident on the accident register, staff frequently reported hitting their head off engine cowlings during safety training sessions.

\subsection{Removal of access panels}

The removal of access panels can either be extremely straightforward or highly tedious. The process entails removing nuts, bolts, clamp rings and gaskets before the panel can be removed. Based on the timings taken, the main deviations observed were removing damaged or seized bolts. When this occurred, task execution times were delayed by up to 1 hour and 56 mins. The main hazard associated with this task is the presence of residual jet fuel. As the panels are being removed, this residual fuel can spill out resulting in either skin or eye contact. In two out of the five observations on removing access panels, staff were found not wearing protective eyewear. In 2018 there was a total of twelve eye 
related accidents. Three of these resulted in loss time ranging between 2 and 12 days.

\section{Task based risk assessment results and monetised risk exposure}

The two shortcuts most observed during the three selected tasks, were the non-usage of required equipment and PPE. In order to monetise the risk exposure for accidents due to these deviations, company accident data were analysed for 2018 .

The costs of accident from the accident data included; the salary paid to the injured party during absent days, the salary paid to the substitute operators, and all medical treatment related fees. The likelihood of each accident scenario was then calculated by dividing the number of relevant injuries by the number of aircraft passing through the organisations hangar during 2018. This allowed an evidence based approximation of likelihood of the accident and resultant monetised values.

\subsection{Task based risk assessment results and monetised risk exposure results}

\subsubsection{Removal of Fuel Filter}

Inadequate use of bump caps were observed as shortcuts when observing and timing the removal of fuel filters. During a visual inspection an actual accident was witnessed, whereby an operator struck their head on the engine cowl. Cowls are commonplace on aircraft and often possess sharp edges, therefore bump caps should be worn by operators when working in their vicinity.

In 2018, there were 6 injuries from not wearing bump caps with a throughput of 50 aircraft. Dividing these two variables leads to an estimated likelihood of $12 \%$. Furthermore, the mean cost of the injuries from not wearing bump caps was estimated to be circa $€ 1,711$.

It was further found that injuries from not wearing bump caps resulted in circa one hour of delay due to locating a qualified substitute operator to complete the task. In comparison The time taken to get the bump cap is less than 8 minutes from task timings, which denotes a cost of $€ 1.17$. This value represents $0.07 \%$ of the total cost of the injury.

Table 6: Estimated risk exposure and timing for deviation

\begin{tabular}{llll}
\hline Path & $\begin{array}{l}\text { Time } \\
\text { estimate }\end{array}$ & $\begin{array}{l}\text { Monetised } \\
\text { risk } \\
\text { exposure of } \\
\text { deviation }\end{array}$ & $\begin{array}{l}\text { Delay } \\
\text { estimate }\end{array}$ \\
\hline $\begin{array}{l}\text { Nominal } \\
\text { path }\end{array}$ & $0.31 \mathrm{hrs}$ & $\mathrm{NA}$ & $7 \mathrm{mins}$ \\
\hline $\begin{array}{l}\text { Deviations: } \\
\text { skin burn } \\
\text { due to } \\
\text { corrosive } \\
\text { lubricant }\end{array}$ & $0.22 \mathrm{hrs}$ & 0.12 & $2 \mathrm{hrs}$ \\
\end{tabular}

\subsubsection{Removal of Electrical Pump}

For the removal of the access panel, the lack of eye protection was identified as a shortcut resulting in the potential for eye injuries from contact with hydraulic fluid. In 2018, there were 15 such accidents. The estimated likelihood of such accidents comes to $30 \%$ and meant costs were circa $€ 1,197.78$.

There were also productivity losses from due to some 1.5 hours of delays again from locating suitably qualified substitute operators to complete the task. The maximum time estimated to procure and wear eye protection was found to be 4 minutes, costing the company $€ 1.38$. This value is some $0.12 \%$ of the total cost of such accidents.

Table 7: Estimated risk exposure and timing for deviation

\begin{tabular}{llll}
\hline Path & $\begin{array}{l}\text { Time } \\
\text { estimate }\end{array}$ & $\begin{array}{l}\text { Monetised } \\
\text { risk } \\
\text { exposure of } \\
\text { deviation }\end{array}$ & $\begin{array}{l}\text { Delay } \\
\text { estimate }\end{array}$ \\
\hline $\begin{array}{l}\text { Nominal } \\
\text { path }\end{array}$ & $2.44 \mathrm{hrs}$ & NA & 4 mins \\
\hline $\begin{array}{l}\text { Deviations } \\
\text { : 2hydraulic } \\
\text { fluid } \\
\text { droplets } \\
\text { resulting } \\
\text { in eye } \\
\text { injury }\end{array}$ & & 0.3 & $1.5 \mathrm{hrs}$ \\
\hline
\end{tabular}

\subsubsection{Removal of Access Panel}

The shortcut observed here was not wearing the gloves while performing the panel removal activity. Panel removal is likely to expose the workers to droplets of corrosive chemicals used 
as lubricants. Contact with such corrosive chemicals can cause skin irritation and burns.

In 2018 five such accidents were recorded involving skin burns. The estimated likelihood was calculated at around $10 \%$. The estimated cost associated to this type of injury was circa $€ 842.19$.

For this type of accident delays cam to about 2 hours again for the locating and briefing qualified substitute operators to complete the task. The time taken to get the required gloves is less than $8 \mathrm{~min}$. This represents a cost of $€ 0.82$ for the company or $0.09 \%$ of the cost associated to the overall injury.

Table 8: Estimated risk exposure and timing for deviation

\begin{tabular}{llll}
\hline Path & $\begin{array}{l}\text { Time } \\
\text { estimate }\end{array}$ & $\begin{array}{l}\text { Monetised } \\
\text { risk } \\
\text { exposure of } \\
\text { deviation }\end{array}$ & $\begin{array}{l}\text { Delay } \\
\text { estimate }\end{array}$ \\
\hline $\begin{array}{l}\text { Nominal } \\
\text { path }\end{array}$ & $1.10 \mathrm{hrs}$ & NA & 4 mins \\
\hline $\begin{array}{l}\text { Deviations: } \\
\text { skin burn }\end{array}$ & $1.02 \mathrm{hrs}$ & 0.1 & $2 \mathrm{hrs}$ \\
due to \\
$\begin{array}{l}\text { corrosive } \\
\text { lubricant }\end{array}$
\end{tabular}

\subsection{Observations about lack of PPE compliance}

During the measurement of the task timings, all operators observed were not wearing bump caps when required. $60 \%$ of the operators were not wearing eye protection when required and $40 \%$ of the operators were not wearing gloves when required.

$\mathrm{Lu}$ et. al. (2015) reports that the non-conformity of PPE usage, can be linked with company factors such as lack of supervision, and insufficient educational programs to show the consequence of workers not wearing PPE. Moreover, it can be associated with personal factors such as culture, gender, age and education level. According to Lombardi, Verma and Brennan (2009), the non-compliance with eye wear requirements can be associated with lack of comfort, logging and scratching of the eyewear. They also reported a lack of safety training as a contributing factors for non use of eye protection.
This study found that mean times taken for operator to procure the right required equipment and PPE took circa 7 extra minutes of their time.

\section{Conclusions}

Shortcuts and deviations are examples human factor, issues affecting the safety and quality of aviation maintenance tasks. This study investigated the costs and delays to a sub set of tasks where short cuts and deviations were observed.

Personnel perceived themselves to be under pressure and therefore willing to use 'acceptable shortcuts' to achieve targets. However, the short cuts did not save money or increase productivity. Based on the cost benefit analysis completed, there was little evidence of productivity gains by using shortcuts. Furthermore a high number of accidents occurred due to these shortcuts which if prevented, would have saved the organisation time and money.

\section{Copyright Transfer Agreement}

\section{References}

Boeing. (2003). Statistical summary of commercial jet aircraft accidents. Seattle WA.

Dhillon, B.S; Y, Liu. (2007). Human error in maintenance: a review. Journal of Quality in Maintenance Engineering 12-1, 21-36.

Drury, C.G. \& Watson, J. (2002) Good practices in visual inspection. Human factors in Aviation maintenance-phase nine, progress report, FAA/Human factors in Aviation maintenance

Drury, C.G. \& Dempsey, P.G. (2012) Human factors and ergonomics Audits G. Salvendy (Ed.), Handbook of Human Factors and Ergonomics (fourth ed.), John Wiley \& Sons, Inc., New Jersey.

Dupont, G. (1997). The Dirty Dozen errors in aviation maintenance. In meeting proceedings of 11 th Federal Aviation Administration Meeting on Human Factors Issues in Aircraft Maintenance and 
Inspection: Human error in aviation maintenance (pp. 45-49). Washington, D.C.: Federal Aviation Administration/Office of Aviation Medicine

Graeber RC and Marx DA. (1993) Reducing human error in aircraft maintenance operations. Proceedings of the flight safety foundation international federation of airworthiness 46th annual international air safety seminar, 147-60. Arlington, VA: Flight Safety Foundation.

Hawkins, F. H. (1993). Human factors in flight. Aldershot, UK: Ashgate

Irish Aviation Authority (IAA). https://www.iaa.ie/who-we-are/about-theirish-aviation-authority. Accessed: March 2019.

Kirwan, B. and Ainsworth, L. K. (1992). A Guide to Task Analysis. CRC Press.

Latorella, K.A. and Prabhu, P.V. (2000) A review of human error in aviation maintenance and inspection. International Journal of Industrial Ergonomics, 26 (2), 133-16

Lombardi, D. A., Verma, S. K., Brennan, M. J. (2009). Factors influencing worker use of personal protective eyewear. Accident Analysis and Prevention 41, 755-762.

Lu, L.; Shi, L.; Han, L.; Ling, $\quad$ L. $\quad$ (2015). Individual and organizational factors associated with the use of personal protective equipment by Chinese migrant workers exposed to organic solvents. Safety Science 76, 168-174.

Mellema, G. M. (2018). Application of Dupont's dirty dozen framework to commercial aviation maintenance incidents. A Dissertation Submitted to the College of Aviation in Partial Fulfilment of the Requirements for the Degree of Doctor of Philosophy in Aviation EmbryRiddle Aeronautical University.

National Transportation Safety Board (1979). Aircraft Accident Report. United States Government. American Airlines, Inc.

Reason, J. (1990). Human error. New York, NY: Cambridge University Press.

Rubin, H. J., \& Rubin, I. S. (2005). Qualitative Interviewing: The Art of Hearing Data (2nd ed.). Thousand Oaks, CA: Sage.

Virovac, D.; Domitrovic, A.; Bazijanac, E. (2017). The Influence of Human Factor in Aircraft Maintenance. PROMET - Traffic \& Transportation. 29 (3), 257.
Skydrol 5 hydraulic fluid https://www.eastman.com/Brands/EAS/Skydr ol/Pages/Product.aspx?pid=71093407 Accessed: March 2019. 